\title{
Large Multiple Primary Retroperitoneal Hydatid Cyst
}

\author{
Pawan Kumar Singh, R.K. Maurya, Manojkumar D. Sonkar \\ Department of Surgery, GSVM Medical College, Kanpur, India
}

\section{A B S T R A C T}

Primary retroperitoneal location of hydatid cyst is extremely rare(0.8\%). We report this recent case of large multiple primary retroperitoneal hydatid disease. JMS $2011 ; 14(2): 66-67$

Keywords: Hydatid cyst, echinococcal disease, retroperitoneal cysts

Hydatid disease or echinococcal disease is a parasitic disease that affects both humans and other mammals and is caused by the larval stages of different species of the tapeworm of genus Echinococcus. ${ }^{1-5}$ It is caused due to ingestion of parasitic eggs. Humans function as accidental hosts, because they are usually a 'dead end' for the parasitic infection cycle. Cysts are mostly located in liver (75\%), lungs, spleen, kidney, brain, etc. ${ }^{1}$ Retroperitoneal involvement was always thought to be secondary to rupture or spillage during surgery of liver hydatid cyst. ${ }^{1,2}$ Primary Retroperitoneal hydatid cyst without other organ involvement was first reported by Lockhart and Sapinza in 1958. ${ }^{1,2}$ Primary retroperitoneal location of hydatid cyst is extremely rare $(0.8 \%){ }^{2,46}$ We report this recent case of large multiple primary retroperitoneal hydatid disease. Diagnosis was made intraoperatively.

\section{Case Report}

A $40 \mathrm{yr}$ old male was admitted with complaint of a huge abdominal swelling initially located in right lumbar region. The swelling had progressed over $30 \mathrm{yrs}$ from the initial size of a cricket ball its present size. Patient had no other abdominal complaints except for a dull aching pain due to tense abdomen. Vitals were stable and multiple bossilated

Address for Correspondence and reprint requests to:

Dr. Pawan Kumar Singh

E-mail:drpawan76@gmail.com

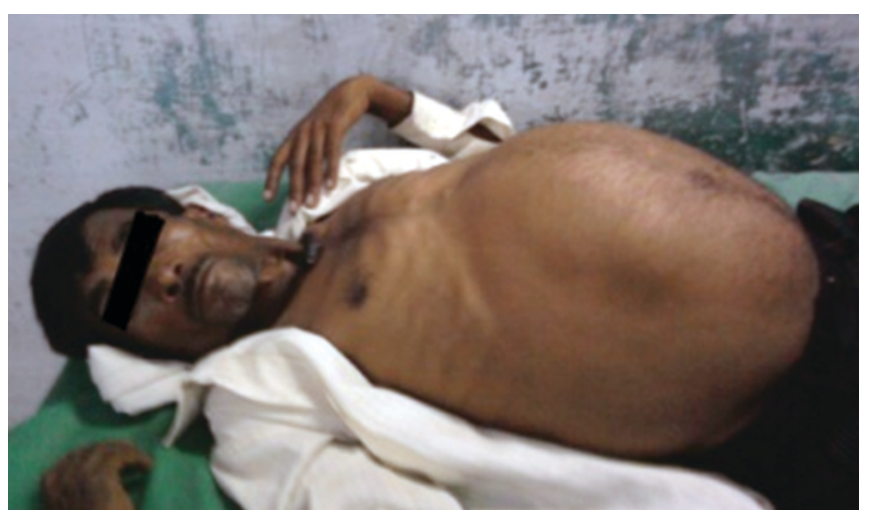

FIGURE: 1 Huge abdominal swelling that patient presented with

cystic swelling were felt with no fluid thrill/shifting dullness on per abdomen examination (Fig. 1).

On USG, multiple cystic cavities with characteristic rosette appearance of cyst within cyst with hydatid sand was noted (Fig. 2). The site of origin of cyst could not be made out due to its huge extent. X- ray chest showed elevation of left hemidiaphragm. On exploration, a large cystic cavity was found with numerous daughter cyst. After careful examination intraoperatively, cavity was found to be arising from retroperitoneum pushing the bowel to right iliac fossa and into pelvic cavity. Two more retroperitoneal cavities were identified, one adjacent to the spleen and another originating from pelvis. Cysts were explored and numerous daughter cyst were evacuated (Fig. 3). Cavities were flushed with 3\% hypertonic saline and povidine iodine solution with 

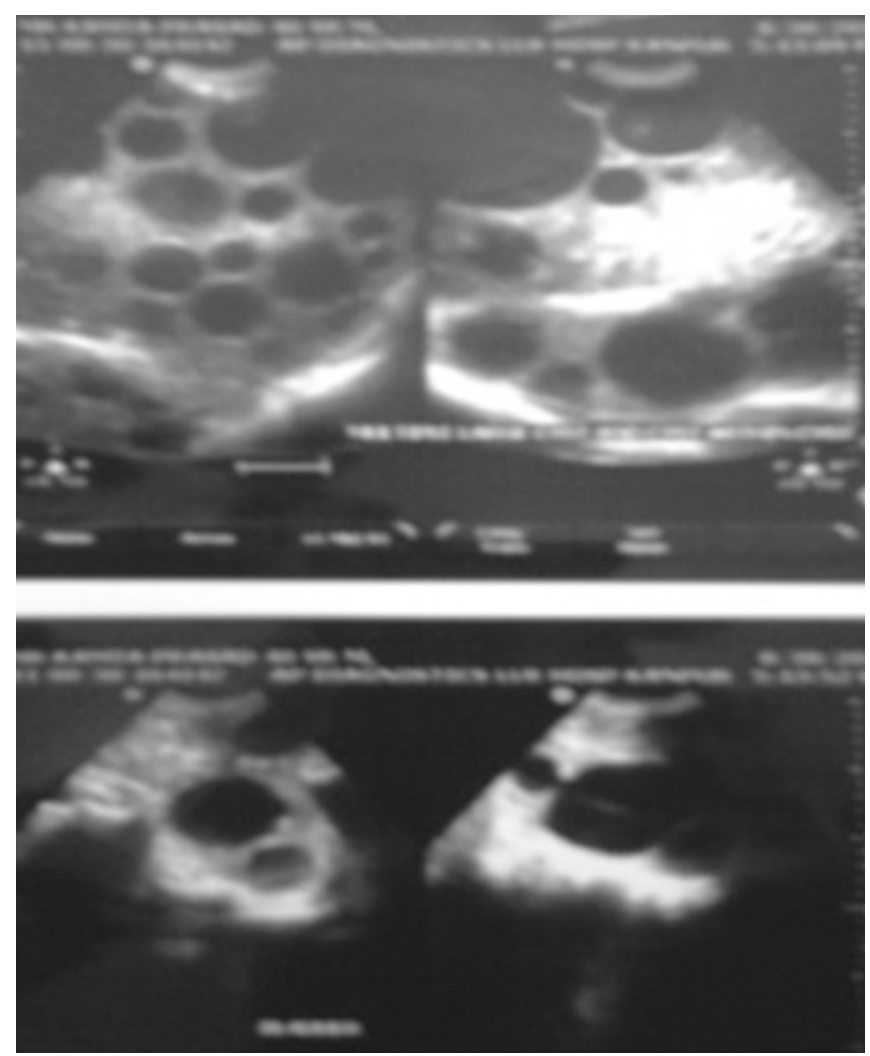

FIGURE 2: Ultrasonography showing characteristic rosette appearance of cyst within cyst with hydatid sand.

marsupialization of the cavities with excision of the redundant portion. Three drains were placed within the cavities \& abdomen closed. Postoperatively patient was discharged with albendazole $400 \mathrm{mg}$ OD for 12 days and regular follow up with serial ultrasound every 3 months.

In conclusion, Retroperitoneal hydatid cyst though always thought to be secondary to rupture or spillage during surgery of liver hydatid cyst. ${ }^{1,2}$ can sometimes be a primary Retroperitoneal hydatid cyst. The later is a very rare presentation with a prevalence of $0.8 \% .{ }^{2.5}$ In most cases they are small in size. Very few case of large multiple primary retroperitoneal hydatid cysts have been reported in literature. ${ }^{1,2,6}$

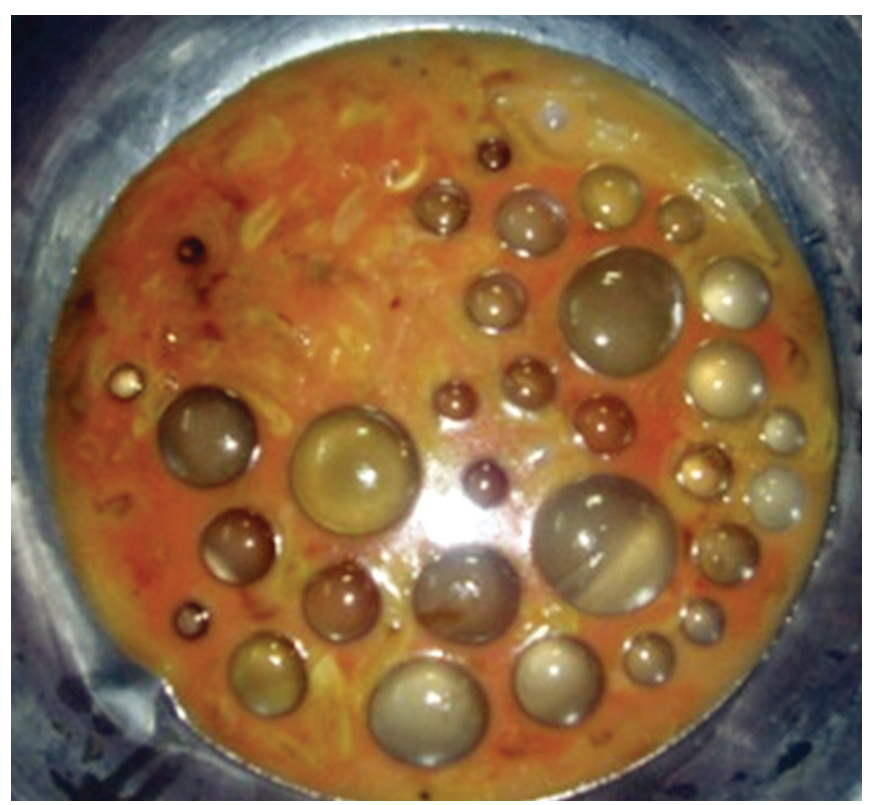

FIGURE 3: Evacuated daughter cysts

\section{References}

1. Mukherjee S, Nigam M, Saraf JC, Primary Retroperitoneal Hydatid Cyst. BritJ Surg 1973;60:916-18.

2. Lockhart J. and Sapinza VC. Primary Retroperitoneal Hydatid cyst. Experta Med 1958;12:968.

3. Beggs I. The Radiology of Hydatid Disease. Am J Roentgenol 1985;145:639-48.

4. El Quakdi M, Ben Fadhel S, Ayed M, Zmerli S, Isolated Retroperitoneal Hydatid cyst. Apropos of 4 cases.J Urol 1988;94:445-8.

5. Courtney M Townsend, R Daniel Beauchamp, B Mark Evers, Kenneth L. Mattox Sabiston Textbook of Surgery: Volume 2.Edtn 18;1494-95.

6. Engin G, Acunas B, Rozanes I, Acunas G. Hydatid disease with unusual localization. Eur Radiol 2000;10:1904-12. 